STUDI

FRANCESI

\section{Studi Francesi}

Rivista quadrimestrale fondata da Franco Simone

174 (LVIII | III) | 2014

Varia

\title{
Aa. Vv., Madame de Staël et le Groupe de Coppet. Écritures intimes dans le Groupe de Coppet
}

\section{Catherine Thomas}

\section{(2) OpenEdition}

1 Journals

\section{Édition électronique}

URL : http://journals.openedition.org/studifrancesi/1535

DOI : 10.4000/studifrancesi. 1535

ISSN : 2421-5856

Éditeur

Rosenberg \& Sellier

\section{Édition imprimée}

Date de publication : 1 novembre 2014

Pagination : 610-611

ISSN : 0039-2944

\section{Référence électronique}

Catherine Thomas, «Aa. Vv., Madame de Staël et le Groupe de Coppet. Écritures intimes dans le Groupe de Coppet », Studi Francesi [En ligne], 174 (LVIII | III) | 2014, mis en ligne le 01 janvier 2013, consulté le 10 décembre 2020. URL : http://journals.openedition.org/studifrancesi/1535; DOI : https://doi.org/ 10.4000/studifrancesi. 1535

Ce document a été généré automatiquement le 10 décembre 2020.

\section{(c)}

Studi Francesi è distribuita con Licenza Creative Commons Attribuzione - Non commerciale - Non opere derivate 4.0 Internazionale. 


\title{
Aa. Vv., Madame de Staël et le Groupe de Coppet. Écritures intimes dans le Groupe de Coppet
}

\author{
Catherine Thomas
}

\section{RÉFÉRENCE}

AA. VV., Madame de Staël et le Groupe de Coppet. Écritures intimes dans le Groupe de Coppet, «Cahiers staëliens», n. 63, 2013, pp. 292.

1 Les six articles qui constituent le dossier thématique du n. 63 des "Cahiers staëliens» sont les actes d'une journée d'étude internationale, organisée le 24 mai 2013 à l'université de Rouen en collaboration avec le CEREdi et l'Institut Universitaire de France, qui se proposait d'explorer le domaine du biographique, lequel suscite fortement l'intérêt de la critique mais reste relativement peu exploré dans les œuvres des écrivains de Coppet. Dans sa présentation, Stéphanie GENAND (pp. 7-10) rappelle cependant l'importance de plusieurs études qui ont abordé la question de l'intime et du biographique chez Benjamin Constant ou Mme de Staël, en soulignant que des axes directeurs forts ont été avancés qui demandent à être encore largement développés. Le dossier s'ouvre par une étude de Valérie, roman mal connu de Mme Krüdener paru en 1803: Fabienne BERCEGOL (pp. 11-34) montre que dans ce «roman de l'intime», qui confie les affres d'une passion illicite, le modèle du roman sentimental du xvIII ${ }^{e}$ siècle se trouve renouvelé par l'influence du mal du siècle propre au début du XIX ${ }^{e}$ siècle. Le passage de la forme épistolaire à celle du journal intime, plus solitaire et plus apaisé, illustre encore l'évolution de l'écriture de soi au tournant de deux siècles. Stéphanie GENAND (pp. 25-50) analyse quant à elle avec précision et justesse les difficultés de l'écriture biographique en ce début de siècle où l'on craint l'impudeur d'un récit qui dévoilerait la vie d'un individu ordinaire, et l'indécence d'occuper de tourments intérieurs un public qui subit encore les violences de l'époque révolutionnaire. Elle 
réhabilite alors la parole personnelle de Mme de Staël qui, tout en évitant les écueils de l'autobiographie, expose dans des œuvres aux formes variées une identité fragmentée, à la fois individuelle et collective, un «intime traversé» qu'accompagne une réflexion théorique sur les enjeux mêmes du récit de vie. Léonard BURNAND (pp. 51-68) retrace ensuite l'histoire éditoriale des Journaux intimes de Benjamin Constant, depuis la version lacunaire et fautive établie par Adrien Constant de Rebecque, publiée en 1887, jusqu'à la remarquable édition critique qui constitue les volumes 6 et 7 des Euvres complètes de Benjamin Constant, en 2002 et 2005. Puis c'est l'œuvre intime de Suzanne Necker qui est mise à l'honneur dans un article intitulé Fabrique de la mémoire chez Suzanne Necker: après avoir montré que la correspondance et les journaux de la mère de Germaine de Staël sont marqués par le désir de mieux se connaître afin de se rapprocher d'un idéal social et moral, Catherine DUBEAU (pp. 69-92) s'appuie sur des textes manuscrits trouvés aux archives du château de Coppet pour dévoiler chez leur auteur un secret espoir d'être lue et un souci de transmission littéraire qui pourraient perturber l'image jusque là admise d'une femme devenue écrivain «malgré elle». Les deux articles suivants portent à nouveau sur la figure de Mme de Staël: Florence LOTTERIE (pp. 93-109) analyse un passage de son journal de jeunesse où il est question d'une lecture faite en famille de La Recherche de la vérité de Malebranche pour envisager les enjeux de la contagion imitative à la fois dans la vie et l'œuvre de la jeune femme, et s'intéresser au «scénario oedipien du Journal», tandis que Damien ZANONE (pp. 111-124) souligne la récurrence de certaines scènes dans Dix années d'exil pour dire l'effroi de Germaine de Staël face à la solitude.

2 Le numéro se poursuit par une rubrique Varia divisée en deux parties: les trois premiers articles reprennent trois conférences prononcées lors de la Journée de Coppet du 2 septembre 2012 consacrée aux «Écritures critiques dans le Groupe de Coppet»: dans La critique staëlienne existe-t-elle?, Stéphanie GENAND (pp. 127-142) souligne les paradoxes d'une pensée critique indépendante et «rétive à toute fixité», qui se déploie dans des œuvres tant fictives que théoriques. L'auteur montre alors comment le modèle de la conversation structure cette critique qui se veut libre et vivante, et la rapproche de la méthode biographique incarnée par Sainte-Beuve. L'étude suivante: «Le personnage selon Benjamin Constant», par François ROSSET (pp. 143-156), souligne encore la mobilité d'un discours critique qui se trouve disséminé dans des œuvres diverses, et retrouve les grandes lignes d'une théorie constantienne du personnage. Enfin l'article de Maria-Pia CASALENA (pp. 157-179) aborde l'écriture de l'histoire chez Sismondi, qui évolue vers la conviction que «les individus sont les miroirs des histoires nationales». Les trois derniers articles abordent des domaines plus divers: José-Luis DIAZ (pp. 181-213) interroge le statut générique de Corinne à la lumière des débats du temps pour éclairer toute la complexité d'un texte qui apparaît comme un «roman-poème». Amélie LEGRAND (pp. 215-238) explore ensuite la polysémie de deux romans contemporains en analysant «les ambiguïtés de l'exemplarité dans La Femme auteur de Félicité de Genlis et Corinne ou l'Italie de Germaine de Staël». Enfin Suzanne HILLman (pp. 239-259) étudie la vision que Mme de Staël offre du christianisme et de l'islam dans les chapitres VIII et X de De la Littérature considérée dans ses rapports avec les institutions sociales. À l'issue de la lecture de ce «Cahier», il est frappant de constater que si seuls les six premiers articles sont consacrés aux écritures de l'intime dans le groupe de Coppet, c'est l'ensemble de l'ouvrage qui nous livre un approfondissement de l'écriture de soi, tant il est vrai que chez ces écrivains la question esthétique est indissociable de l'expérience personnelle. 